\title{
Sea trials of MARTIN - a European survey AUV
}

\author{
Henriksen, Lars; Bjerrum, A.; Ishoy, A.
}

\section{Published in:}

Conference Proceedings of OCEANS '95

Link to article, DOI:

10.1109/OCEANS.1995.528674

Publication date:

1995

\section{Document Version}

Publisher's PDF, also known as Version of record

Link back to DTU Orbit

Citation (APA):

Henriksen, L., Bjerrum, A., \& Ishoy, A. (1995). Sea trials of MARTIN - a European survey AUV. In Conference Proceedings of OCEANS '95 (Vol. Volume 3, pp. 1439-1445). IEEE.

https://doi.org/10.1109/OCEANS.1995.528674

\section{General rights}

Copyright and moral rights for the publications made accessible in the public portal are retained by the authors and/or other copyright owners and it is a condition of accessing publications that users recognise and abide by the legal requirements associated with these rights.

- Users may download and print one copy of any publication from the public portal for the purpose of private study or research.

- You may not further distribute the material or use it for any profit-making activity or commercial gain

- You may freely distribute the URL identifying the publication in the public portal

If you believe that this document breaches copyright please contact us providing details, and we will remove access to the work immediately and investigate your claim 


\title{
Sea Trials of MARTIN - A European Survey AUV
}

\author{
Lars Henriksen, Institute of Automation, Technical University of Denmark, Building 326, DK-2800 Lyngby, Denmark, \\ lh@iau.dtu.dk \\ Anders Bjernum and Anders Ishoy, Maridan ApS, Usserød Kongevej 31, DK-2970 Hersholm, Denmark, \\ maridan@inet.uni-c.dk
}

\begin{abstract}
The Unmanned Untethered Underwater Vehicle MARTIN was launched by Maridan, Denmark in 1995. The design was based on the European AUV MARIUS (1992). MARTIN is being instrumented for oceanographic and industrial surveys including inspection of offshore installations (Pipelines, Sea Cables). Sea Trials in open water are currently being performed.
\end{abstract}

A new navigation system has been developed for MARTIN. The low-drag, flat-fish shaped, modular designed hull has been thoroughly tested in a towing tank and in the open sea. The hydrodynamic parameters were used in computer simulations of vehicle dynamics. An autopilot based on an adaptive controller takes care of the low level control of rudders and thrusters. Path Control including Obstacle Avoidance ensures a smooth trajectory following capability. Mission Control is performed with a human operator in the loop (UUV-mode).

The Obstacle Avoidance system is based on the SeaBat multi-beam sonar (Reson, Denmark). Noise filtering, image analysis and path planning software was developed by the Institute of Automation, Danish Technical University in a co-operation with Reson AS and Maridan ApS.

The paper includes a description of the navigation system, results from simulations and preliminary results from the first sea trials. Furthermore attempts to use sonar images to dead-reckoning will be discussed.

\section{Introduction}

The AUV (Autonomous Underwater Vehicle) called MARTIN was developed for oceanographic and industrial surveys in shallow water down to 100 metre water depth. The depth rating is planned to be upgraded to 600 metre to cover requirements from the oil industry. The hull and basic power and propulsion systems are based on the prototype vehicle MARIUS ${ }^{1}$ developed under the European Community Programme MAST (Marine Science and Technology). Tank tests and sea trials with MARIUS have proved the efficiency of the flatfish shaped low-drag hull ${ }^{2}$ (Figure 1). A modular design of the instrumentation with electronics and sensors arranged in separate pressure compartments was intro- duced in MARIUS $^{3}$. The same design principle was adopted for MARTIN due to its flexibility to different operation modes and easy installation of specific payload instrumentation. A new type non-metallic GRPbased composite material was applied for pressure compartments leading to considerable weight reduction.

Mission Control is taken care of by a human operator by sending on-line survey commands to the vehicle. The low level Path Control and steering commands, however, is automated. The communication link may be a fibre optic tether that allows transmission of video and sonar images (Tether mode), which is used for testing the navigation system. For oceanographic and industrial surveys the vehicle can be operated with acoustic communication between the vehicle and the human operator onboard a surface vessel following the vehicle (UUVmode).

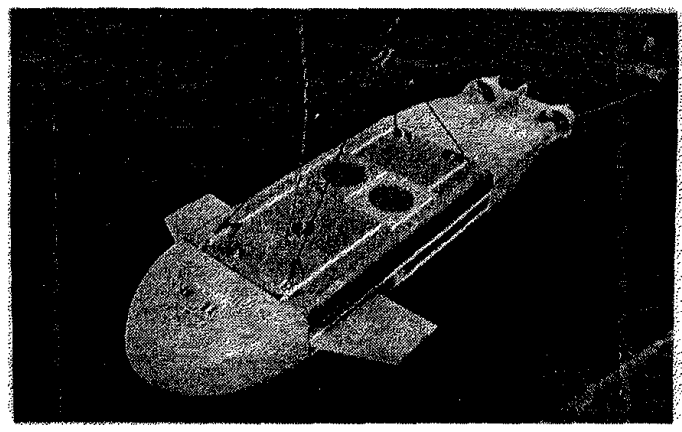

Figure 1: The two vehicles MARIUS (Photo) and MARTIN have the same shape with a length of 4.5 metre.

The four operation modes commonly referred to for unmanned systems are: ROV-mode, Tether mode, UUV-mode and AUV-mode (Figure 2). At present MARTIN can be operated either in Tether mode or UUV-mode, so strictly spoken MARTIN should be termed as an UUV instead of AUV. However, the term AUV has been generally adopted for any unmanned vehicle that has no cable connection to the surface.

Operations in UUV-mode with a man-in-the-loop for Mission Control may look as a limitation compared to complete autonomous operations (AUV-mode) that is 


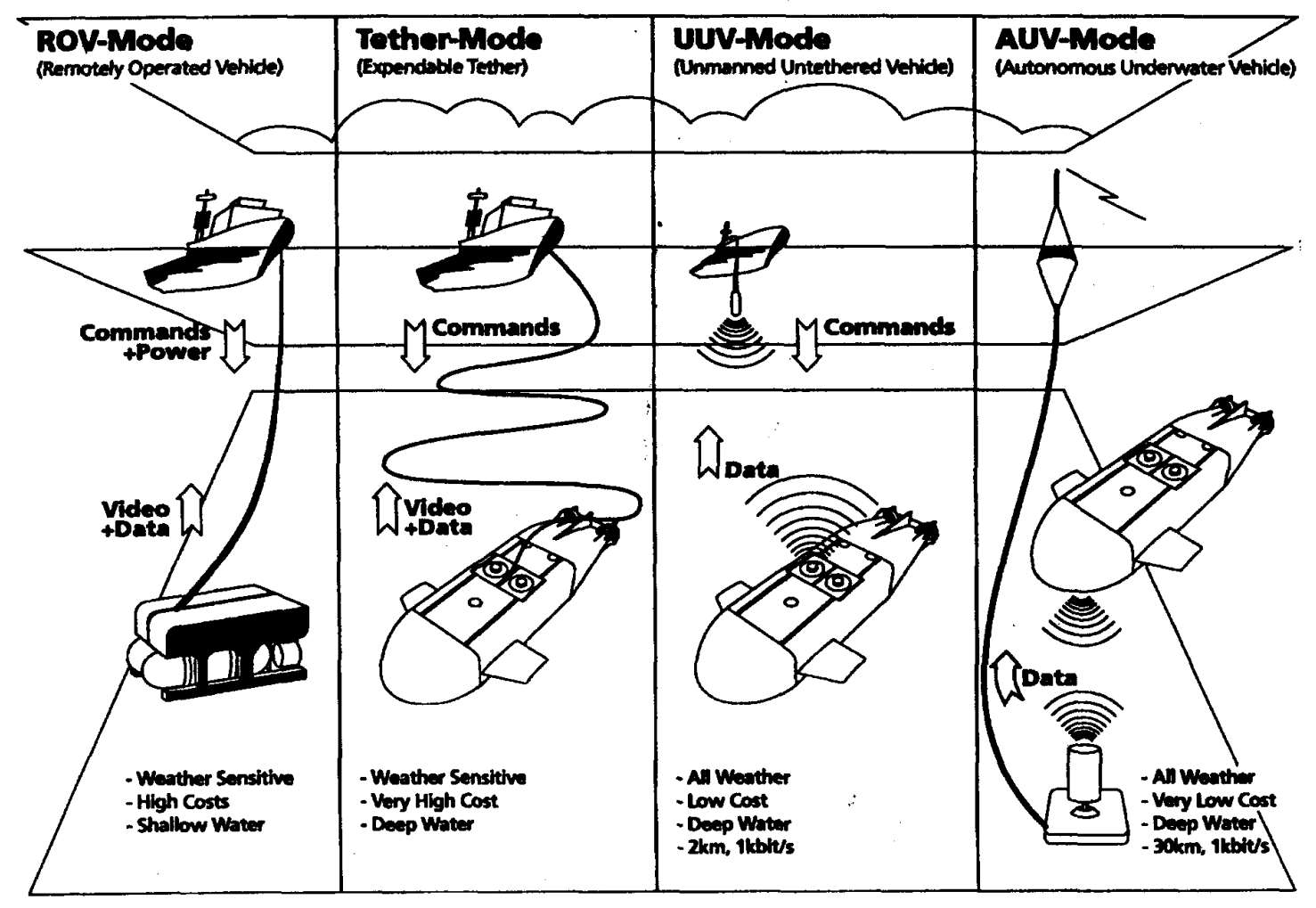

Figute 2: Different modes of operation from ROV to AUV with increasing autonomy

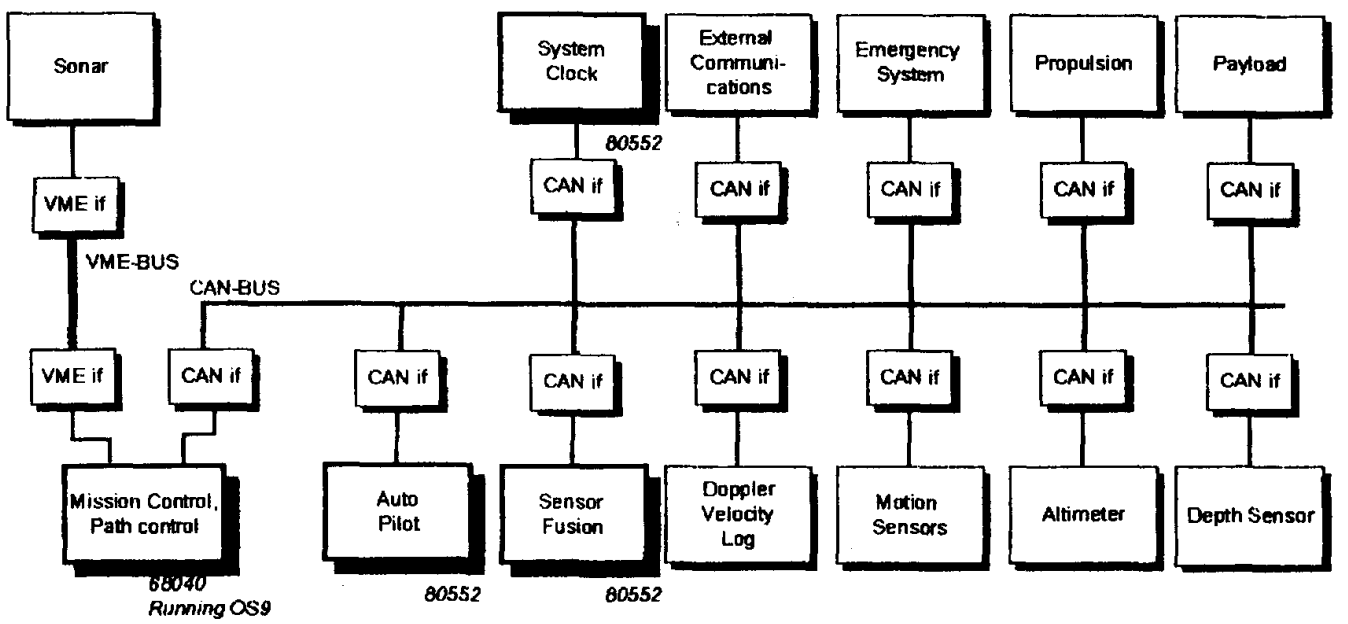

Figure 3: Instruments and Subsystems are connected to VME- or CAN-nodes 
being developed for MARIUS ${ }^{45}$. However, for most oceanographic and industrial surveys there is no demand to operate without a mother vessel. The presence of the mother vessel allows on-line quality assurance of survey data, and it improves vehicle positioning in particular for a long cruise. These advantages are more important for practical survey than possible savings by replacing the surface vessel with communication buoys. In fact, UUVoperations are expected to become economic feasible compared to ROV-operations because minor surface vessels without dynamic positioning (DP) can be applied. Today the maximum distance for acoustic communication in a horizontal channel is $2 \mathrm{~km}$, but future UUV-surveys may be carried out at a distance of $30 \mathrm{~km}$ or more from the operator. This might be possible as acoustic network communication systems are being improved.

Because of baud rate limitations in any acoustic communication it is mandatory to have a navigation system onboard the vehicle for path control during the survey. The navigation system returns online navigation data to the surface console for information but no active steering commands are required from the operator. The navigation system is able to guide MARTIN along a trajectory in accordance with the survey requirements. The simplest trajectory is a straight line that is used for line surveys, such as inspection of seabed cables or pipelines. For bathymetry and environmental monitoring the trajectory may include a set of parallel lines connected by U-turns.

The systems and instrumentation onboard the vehicle can be divided as follows:

Power and Propulsion System including batteries, thusters, control surfaces and actuators

Navigation System including the three control levels Mission Control, Path Control and Servo Control.

Payload System insluding video and specific survey sensors.

The following sections describe the design and test of the Navigation System. Section 2 describes the instrumentation required for navigation, section 3 describes the controllers, planners and other subsystems included in the navigation system.

\section{Instrumentation}

\subsection{Computer configuration}

MARTTN is being equipped with a wide range of instruments and subsystems for path control. The network configuration shown in (Figure 3) gives access for all subsystems to the latest updated information and has a similar function as a blackboard) ${ }^{7}$.
The sonar is connected to the high data rate VME bus, while all other instruments and subsystems are connected to a CAN computer network with the following specifications:

\begin{tabular}{ll}
\hline & \multicolumn{1}{c}{ CAN Network Performance } \\
\hline Error Detection & $\begin{array}{l}\text { Less than } 3 \text { undetected errors } \\
\text { per billion detected errors. } \\
\text { Less than } 0.5 \text { milliseconds }\end{array}$ \\
$\begin{array}{l}\text { Latency } \\
\text { Differential Termi- } \\
\text { nation }\end{array}$ & $\begin{array}{l}62 \text { Ohm. Multiple bit Sampling. } \\
\text { Data Rate }\end{array}$ \\
Message size & Max. 8 bytes \\
Architecture & All Messages are broadcasted \\
\hline
\end{tabular}

The CAN net was selected due to it's the efficiency in passing short messages and parameters. A build-in message arbitration does not impose invalidation of bits, because collisions do not reduce the effective bandwidth. Thus the message arbitration allows high-priority messages to be transferred without delay. The build-in error detection saves programming time by its automatic handling of minor errors. In case of a long disturbance the bus interface will flag the error and eventually go into bus-off-state.

Examples of short messages are: Servo and motor RPM setpoints, watchdog functions, position and motion data. The broadcast feature enables all nodes to read all messages. This is especially relevant for including synchronizers, error observers and general monitors and future expansions.

As shown in Figure 3 several nodes are connected in the CAN net, the nodes are physically located in separate pressure compartments. Each node includes a general purpose interface that was build on a circular board based on a Philips 80C552 microcontroller. The interface board called CIP (Communication, Interface and Power) includes digital $\mathrm{L} / \mathrm{O}, \mathrm{D} / \mathrm{A}, \mathrm{A} / \mathrm{D}$ and $\mathrm{RS} 232 / \mathrm{RS} 422$ converters. The flexibility of the CAN net enables implementation of any function in any pressure compartment.

The Path Controller was implemented on a VME single board computer with a Motorola 68040 microprocessor running OS9. The computational power of the VME computer allows later implementation of Mission Control software when the vehicle should operate in AUVmode.

\subsection{Forward Looking Sonar}

A high resolution multi-beam sonar is used for obstacle detection ${ }^{8}$. The sonar was originally developed for use in ROV's, but the compact design, low power consumption and high resolution make it suitable for AUV's. 

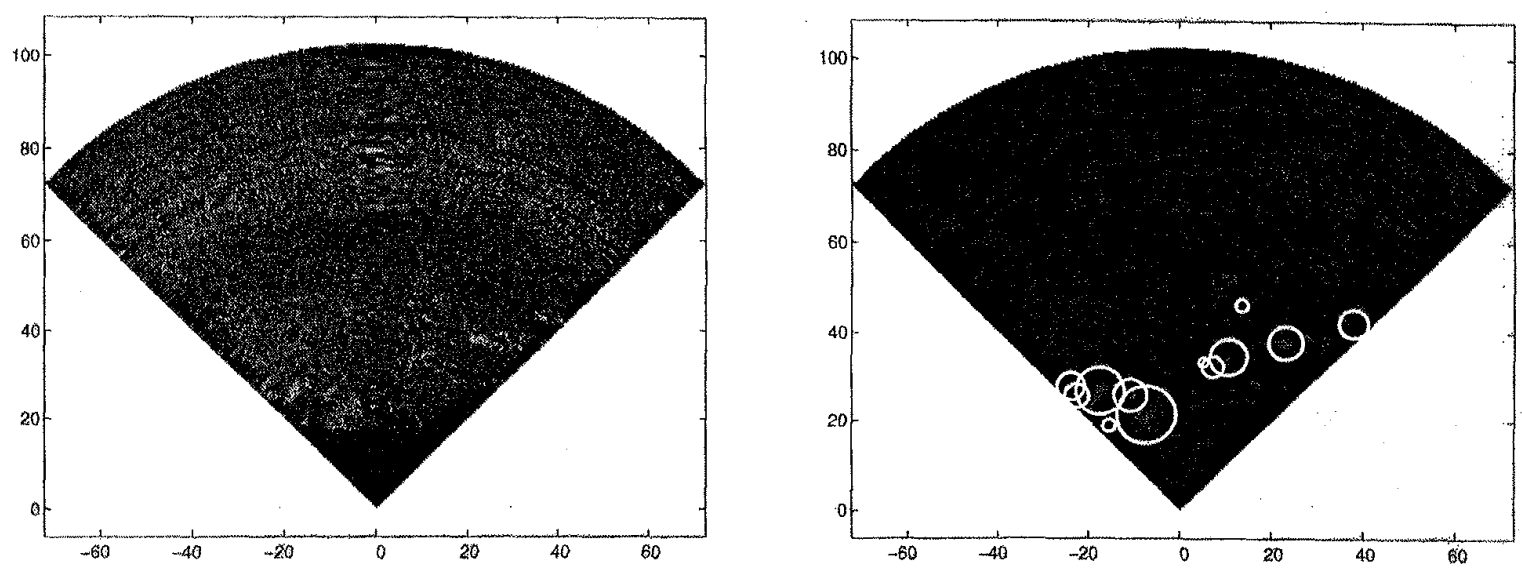

Figure 4: Left - Sonar image recorded 6 metre above the sandy bottom (the sonar was down-tilted 12 degrees). Right Processed version of the same sonar image. Obstacles are marked in circles.

The 1 Mbytes/s sonar interface is provided by a VME computer that also performs synchronization and digitization of the sonar signals. The computer filters and resolves the sonar image into a number of distinct obstacles, described as cylinders in global co-ordinates (Figure 4). Image filtering, obstacle detection and path finding algorithms were developed by the Institute of Automation, Technical University of Denmark in a cooperation with Reson AS and Maridan ApS.

Once detected, the obstacles are followed through consecutive sonar images. The obstacle data are broadcasted on the CAN net. Recorded sonar data from sea tests were used to test the obstacle detection. The detection is reliable with a small tendency to detect false obstacles.

In addition to obstacle detection the sonar data may also be used when docking to a cage for vehicle recovery. The motion relative to the cage can be determined very accurately at close distance compared to conventional homing systems based on USBL. Another possibility when using the high resolution sonar is to deduce dead reckoning by image correlation as discussed in section 3.2 .

\subsection{Positioning System}

A very accurate positioning system for cruising is required for oceanographic and industrial surveys. Accuracy of less than 1 metre is expected for MARTIN with the following type of instrumentation:

- Doppler Velocity Log for determination of absolute speed over the seabed

- Inertia platform including a laser gyro for determination of heading

- USBL-tracking from the mother vessel with satellite positioning (DGPS).

The positioning system for cruising has not yet been implemented on MARTIN. Up to now sea trials was using a simple tracking system.

The performance of the positioning system and the ad1442 ced use of sonar for docking and dead reckoning for
MARTIN will be published when experiences from sea trials are obtained.

\subsection{Line Tracking}

A frame with coils for sensing the magnetic response is used for tracking cables and pipelines ${ }^{10}$. The tracking sensor is well known for use on ROVs; the only difference for use on MARTIN is that the human operator is not included in the loop. The output from the tracking sensor is used directly by the navigation system to calculate input to the autopilot.

Line tracking is simple as long as the tracking system receives a response from the pipeline or cable. If the contact is lost, e.g. because of burial deeper than one meter, the vehicle continues its course while trying to get contact. If contact is not re-established in a short time the human operator must guide the vehicle back to the assumed position of the pipeline or cable. This might require a skilled operator who shall communicate directly with the autopilot. This operation remains to be tested at sea.

\section{Navigation}

The control hierarchy for MARTIN can be divided in three levels $^{11}$ (Figure 5):

- Mission Control Level that generates waypoints for the survey and takes care of emergency situations. This level is at present performed partly with a manin-the-loop (UUV-mode).

- Path Control Level includes the following subsystems: Trajectory Following, Obstacle Detection, Path Planning and Reactive Avoidance.

- Servo Control Level including the Autopilot and actuators for control surfaces. 


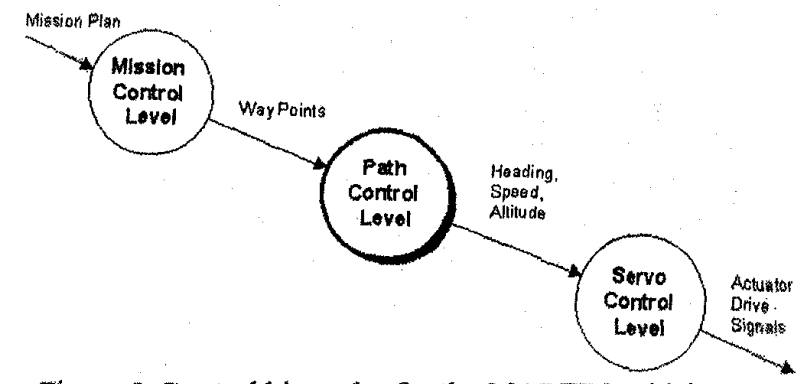

Figure 5: Control hierarchy for the MARTIN vehicle.

Decoupling of Path Control and Servo Control is a pragmatic approach that is believed to be safe. It allows suspension of individual control functions during sea tests. A possible drawback could be the limited bandwith compared to a coupled guidance system ${ }^{12}$, however, the solution selected for MARTIN seems to work efficiently. This was confirmed by integrated simulations of the Path Controller and a simple vehicle model.

The CAN net supports suspension of certain control functions during test. Different levels of the control system can be overruled by external commands. The following input commands can be overruled by the operator:

\begin{tabular}{l|l|l} 
Input & $\begin{array}{l}\text { Controller } \\
\text { Mission } \\
\text { Controller }\end{array}$ & $\begin{array}{l}\text { Waypoints Halt, } \\
\text { Surface }\end{array}$ \\
\hline $\begin{array}{l}\text { Waypoints, } \\
\text { Halt, Surface }\end{array}$ & $\begin{array}{l}\text { Path } \\
\text { Controller }\end{array}$ & $\begin{array}{l}\text { Heading, Speed, } \\
\text { Altitude }\end{array}$ \\
\hline $\begin{array}{l}\text { Heading, Speed, } \\
\text { Altitude }\end{array}$ & Autopilot & $\begin{array}{l}\text { Actuator Drive } \\
\text { Signals (Setpoints } \\
\text { for thrusters and } \\
\text { control surfaces) }\end{array}$ \\
\hline
\end{tabular}

\subsection{Mission Control}

Presently a minimum solution for the Mission Control is implemented. The system initializes the vehicle and passes a list of waypoints to the Path Controller. It also enables launch and recovery procedures and emergency actions. Diagnostics are only dealt with in a rudimentary way, but the system allows implementation of safety procedures as experience from sea trials is obtained.

\subsection{Path Control}

The Path Controller performs trajectory following and related routines (Figure 6) that are required to guide the vehicle safely when cruising close to the seabed. After calculation of a Path plan based on early detected obstacles, the desired trajectory may be modified by the Reactive Avoidance Controller due to late detected obstacles.

\section{Path Finder}

The trajectory to be followed is described as a set of waypoints defined in global co-ordinates. In case of current the vehicle (and the sonar) heading must be compensated for driftage. A compensated waypoint $100 \mathrm{me}$ tre from the vehicle (the sonar range) is termed the Goalpoint (Figure 7). The shortest free path to the Goalpoint is calculated by the Path Finder. Because of the wide sonar angle ( 90 degrees) the Goalpoint will be in sight even if the vehicle heading should deviate up to 45 degrees due to driftage.

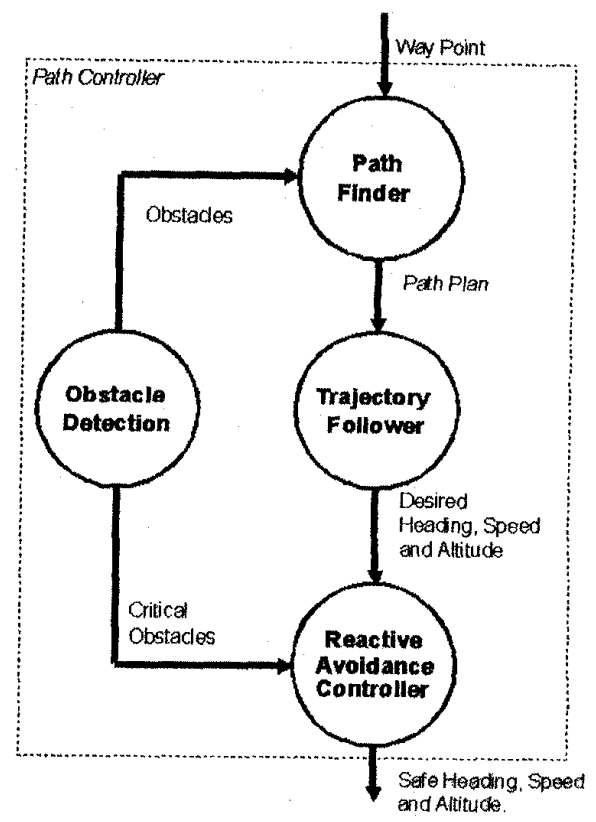

Figure 6: Flow chart of the Path Finder.

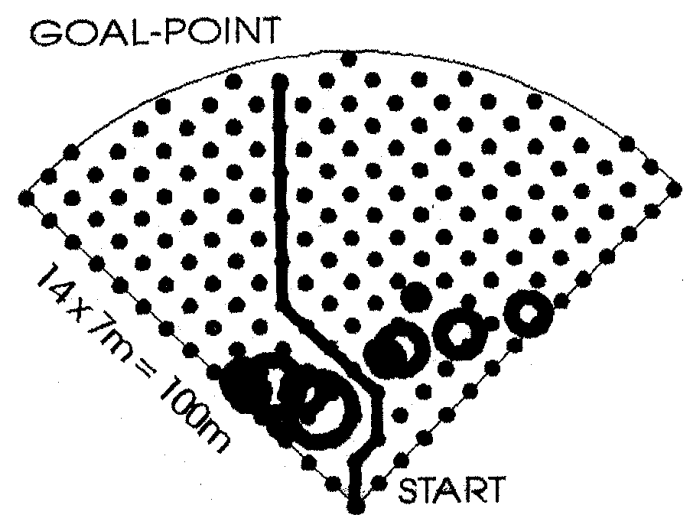

Figure 7: The Path Finder calculated a free path to the Goalpoint 100 metre ahead of the vehicle.

A square grid of one characteristic vehicle length ( 7 metre) is defined. Each grid node is assigned "Free" or "Occupied" depending on the information from the Ob- 
stacle Detection System (Moving obstacles like fish are not included at present). The shortest free route to the Goalpoint is found.

\section{Trajectory Follower}

The Trajectory Follower starts executing the path plan, but as the obstacle image is updated a new path plan is generated (every 1-7 second), and the Trajectory Follower shifts to the new plan.

\section{Reactive Avoidance Controller}

The path plan may be overruled by the Reactive Avoidance Controller that changes heading or altitude when an object is coming too close. The selection of evading strategy is similar to a fuzzy logic principle ${ }^{13}$. Simulation of the Reactive Avoidance Control with a model of MARTIN results in a smooth and safe route (Figure 8).

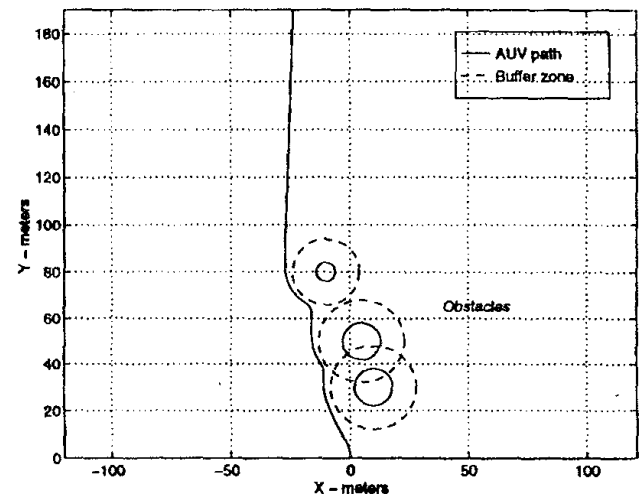

Figure 8: Simulation of the Reactive Avoidance Controller.

The Reactive Avoidance Controller is only active when the Path Finder fails or new obstacles show up too late to be taken into account by the Path Finder.

The Path Finder is being tested at sea with artificial obstacles (soft wrapping plastic with air bubbles that gives good reflections). The Reactive Avoidance Controller being disabled during the test.

\section{Obstacle Detection}

The Obstacle Detector provides information on position and size of objects in front of the vehicle. Obstacle positions must be updated in global co-ordinates fast enough to allow evasion. The data must be reliable to avoid hazards from hidden obstacles and unnecessary moves caused by false obstacles.

Raw sonar data are generally of poor quality due to underwater noise. Furthermore the echo signals depend on the surface roughness of the obstacies. Most of the acoustic energy is dispersed and only a small amount is returned to the sonar. This might be critical especially in near bottom operations where bottom reverberation is the dominant signal. To compensate for these effects filtering and equalizing of the sonar image is carried out before search for obstacles (Figure 4).

Equalization reduces bias effects from bottom reverbaration, interference effects from other acoustic equipment and effect from sonar inconveniences such as different beam sensitivity and deviations in the time varying gain. Filtering suppresses noise and echoes from very small objects (fish) that are considered non-critical.

A two level threshold for Object Detection is proposed. On the first level the positions of obstacles are identified and on the second level the sizes are calculated. Due to noise and disturbances obstacles may disappear from one frame to the next, and the positions of detected obstacles are noise corrupted. By use of event driven $\mathrm{Kal}-$ man filters the detection can be improved by stacking obstacles from a number of subsequent sonar frames. This requires information on vehicle movements.

The result of the equilization, filtering and tresholding is seen to the right on Figure 4. Bottom reverberation, dropouts and inconveniences from the time varying gain are greatly reduced. Furthermore noise is lowered significantly leaving a homogeneous image where the objects are easily visible. During the ongoing sea test different parameters of the image processing algorithms are tuned and the range of reliable detections assessed. Also the influence of surface reflections (ghosting) is addressed.

\subsection{Servo Control}

An autopilot closes the loop around the propulsion system (thrusters and control surfaces). The aim of the autopilot is to control speed, heading, and altitude as commanded continuously by the Path Controller. The autopilot returns rudder, elevator, and aileron angles and propeller RPM. The commands transmitted to the autopilot are compensated for driftage due to water current.

Speed is, as a first approximation, controlled by a deterministic relation between speed and propeller RPM. Control of heading and altitude is based on a non-linear, model-referencing, adaptive controller, originally developed for heading control of surface vessels ${ }^{14}$. Heading and altitude are controlled by two independent control algorithms. The altitude is controlled by commanding the pitch angle equal to a linear combination of the pitch rate and the difference between the desired and the actual altitude.

The autopilot was tested against a computer model of MARTIN, and the result was indeed satisfactory. Despite the non-linear behaviour and dynamic instability of the vehicle, the autopilot gives smooth response with no overshoot

The autopilot is running on a Phillips $80 \mathrm{C} 552$ microcontroller on a CIP board. 


\section{Acknowledgement}

The project was carried out under the Nordic PING cooperation (Projects on Instrumentation, Navigation and Guidance Systems for AUVs).

The research in navigation using sonar image processing was funded by the Danish Technical Research Council (STVF Contract 16-5245-1 OS). The work concerning AUV design and testing was funded by EC (Contract MAST-CT90-0059 and MAS2-CT92-0021) and by EUROMAR (EU 1249 STIRLING AUV).

\section{Conclusion}

The flatfish shaped low-drag hull used for the EC vehicle MARIUS has proved efficient for small survey AUV's. A second vehicle MARTIN is currently being tested at sea.

MARTIN characteristics are

- Depth rating 100 metre (to be upgraded to 600 metre to meet requirements from the oil industry).

- Same flatfish shaped low-drag hull as MARIUS, but with reduced dry weight.

- Decentralized instrumentation located in separate low-weight pressure compartments

- Dynamic broadcasting of navigation data using a CAN computer network.

- Accurate positioning and navigation for long cruise based on a mother vessel following the vehicle (UUV-mode)

The sea test is still ongoing, but simulation and preliminary tests have indicated excellent performance of the navigation system.

\section{References:}

${ }^{1}$ Ayela A., Bjerrum A., Bruun S., Pascoal A., Pereira FL., Petzelt C., Pignon J-P., "Development of a SelfOrganizing Underwater Vehicle - SOUV". MASTDays and EUROMAR Marked, Sorrento, Italy, November 1995 .

${ }^{2}$ Aage C., Smitt L.W. "Hydrodynamic Manocuvrability Data of a Flatiish Type AUV". Proceedings of the OCEANS'94 IEEE Conference, Brest, France, September 1994.

${ }^{3}$ Egeskov P., Bjerrum A., Aage C., Pascoal A., Silvestre C., Smitt L.W. "Design, Construction and Hydrodynamic Testing of the AUV MARIUS". Proceedings of the 1994 Symposium on Autonomous Underwater Vehicle Technology, AUV94, IEEE Oceanic Engineering Society, Cambridge, USA, July 1994.
${ }^{4}$ Bizingre C., Oliveira O., Pascoal A., Pereira F., Pignon J., Silvestre C., de Sousa J.B. "Design of a Survey Management System for the Autonomous Underwater Vehicle MARIUS"*. Proceedings of the 1994 Symposium on Autonomous Underwater Vehicle Technology, AUV94, IEEE Oceanic Engineering Society, Cambridge, USA, July 1994.

${ }^{5}$ Pascoal A., Fryxell D., Oliveira P., Silvestre C. "Integrated Design of Navigation, Guidance and Control Systems for Unmanned Underwater Vehicles". Proceedings of the OCEANS'94 IEEE Conference, Brest, France, September 1994.

${ }^{6}$ Pignon J.P., Bizingre C., "Multiple Agent Architecture for Intelligent Command and Control System of AUV's: Application to the MARIUS Vehicle". Proceedings of the OCEANS'94 IEEE Conference, Brest, France, September 1994

'Englemore J. ,Morgan T., "Blackboard Systems", Addison Westley, 1989.

${ }^{8}$ SOUV Technical Report, "ODS Development". Reson AS, Denmark, Report no 2, September 1993 (Not published).

${ }^{9}$ Henriksen, L. "Real-Time Underwater Object Detection Based on an Electrically Scanned HighResolution Sonar". Proceedings of the 1994 Symposium on Autonomous Underwater Vehicle Technology, AUV94, IEEE Oceanic Engineering Society, Cambridge, USA, July 1994.

${ }^{10}$ Egeskov P., Bech M., Aage C., Bowley R., "Pipeline Inspection using an Autonomous Underwater Vehicle". 14th Offshore Mechanical and Arctic Engineering Conference, OMAE'95, Copenhagen, Denmark, June 1995.

${ }^{11}$ SOUV Technical Report, "Contributions to the overall Architecture for the Survey Management System (MMS)". COWIconsult, Denmark, Report no 22278-TR1, March 1993 (Not published).

${ }^{12}$ Fryzell D., Oliveira P., Pascoal A., Sylvestre C., Kaminer I., "Navigation, Guidance and Control of AUV's. An Application to the MARIUS vehicle": 3 rd IFAC Workshop on Control Applications in Marine Systems CAMS'95 Trondheim, Norway, May 1995.

${ }^{13}$ Steer B., Larcombe M. "A Goal seeking and Obstacle Avoiding Algorithm for Autonomous Mobile Robots": Proceeding of the 1991 IEEE Intemational Conference on Robotics and Automation.

${ }^{14}$ Bech M., "The Racal Decea Pilot Adaptive Autopilot", The International Association of Science and Technology for Development, IASTED, Lyngby, Denmark, 1983. 